\title{
Effectiveness of dietary interventions on cardio-metabolic risk factors in patients with nonalcoholic fatty liver disease: a systematic review and meta-analysis of randomized controlled trials
}

\author{
Maryam Ghadimi i,b, Reihaneh Mohammadib, Elnaz Daneshzadc, Bobak Moazzamí, \\ Zinat Mohammadpour ${ }^{b, d}$
}

Tehran University of Medical Sciences, Tehran, Iran; Imam Khomeini Hospital Complex, Tehran University of Medical Sciences, Tehran, Iran; University of Adelaide, Australia

\section{Abstract}

\begin{abstract}
Background Dietary modification is considered as one of the main strategies in the management of nonalcoholic fatty liver disease (NAFLD). The objective of this study was to systematically investigate the effect of dietary interventions on the cardio-metabolic risk factors, including lipid profile and insulin resistance in this population.
\end{abstract}

Methods We searched electronic databases of PubMed and Scopus until January 2020 and included randomized controlled trials that compared the effect of dietary modifications vs. control on lipid profile and insulin resistance in patients with NAFLD. The random-effect analysis was performed to calculate pooled weighted mean differences (WMD).

Results Our finding showed that serum triglycerides (TG) ( $\mathrm{n}=5$, WMD $-38.50 \mathrm{mg} / \mathrm{dL}$, $95 \%$ confidence interval $[\mathrm{CI}]-61.68$ to $-15.31 ; \mathrm{P}=0.001)$ and total cholesterol (TC) $(\mathrm{n}=4$, WMD -18.70 $\mathrm{mg} / \mathrm{dL}, 95 \% \mathrm{CI}-34.85$ to $-2.53 ; \mathrm{P}=0.023$ ) decrease following diet intervention along with marginally significant weight reduction $(\mathrm{n}=5$, WMD $-3.61 \mathrm{mg} / \mathrm{dL}, 95 \% \mathrm{CI}-7.25$ to $0.04 ; \mathrm{P}=0.053)$. There was no change in the homeostatic model assessment for insulin resistance, high- and low-density lipoprotein $(\mathrm{LDL})$ levels $(\mathrm{P}>0.05)$. Subgroup analysis revealed that Mediterranean diet reduced TG $(\mathrm{n}=2$, WMD $-57.52 \mathrm{mg} / \mathrm{dL}, 95 \% \mathrm{CI}-75.73$ to $-39.31 ; \mathrm{P}<0.001)$ and weight $(\mathrm{n}=2$, WMD $-7.59 \mathrm{Kg}, 95 \% \mathrm{CI}-13.53$ to -1.66; $\mathrm{P}=0.012)$, and also increased LDL level $(\mathrm{n}=2$, WMD $29.73 \mathrm{mg} / \mathrm{dL}, 95 \% \mathrm{CI} 13.82-45.65$; $\mathrm{P}<0.001)$. However, standard hypocaloric diet improved TC $(\mathrm{n}=2$, WMD $-23.20 \mathrm{mg} / \mathrm{dL}, 95 \% \mathrm{CI}$ -36.96 to $-9.44 ; \mathrm{P}=0.001$ ) and $\mathrm{LDL}$ ( $\mathrm{n}=2$, WMD $-16.82 \mathrm{mg} / \mathrm{dL}$, 95\%CI -29.44 to $-4.19 ; \mathrm{P}=0.009$ ).

Conclusion Dietary modifications may improve serum TG, TC, and obesity in NAFLD.

Keywords Nonalcoholic fatty liver disease, dietary interventions, cardio-metabolic risk factors, insulin resistance, lipid profile

Ann Gastroenterol 2021; 34 (2): 1-14
aDepartment of Clinical Pharmacy, Faculty of Pharmacy, Tehran University of Medical Sciences, Tehran, Iran (Maryam Ghadimi); biver Transplantation Research Center, Imam Khomeini Hospital complex, Tehran University of Medical Sciences, Tehran, Iran (Maryam Ghadimi, Reihaneh Mohammadi, Bobak Moazzami, Zinat Mohammadpour); 'Department of Community Nutrition, School of Nutritional Sciences and Dietetics, Tehran University of Medical Sciences, Tehran, Iran (Elnaz Daneshzad); ${ }^{\mathrm{d} A d e l a i d e ~ M e d i c a l ~ S c h o o l, ~ F a c u l t y ~ o f ~ H e a l t h ~ a n d ~}$ Medical Sciences, University of Adelaide, Adelaide, Australia (Zinat Mohammadpour)

Conflict of Interest: None

Correspondence to: Zinat Mohammadpour, Level 5, AHMS Building, Cnr North Tce and George St, Adelaide, 5005, Australia, e-mail: zinat. mohammadpour@adelaide.edu.au

Received 13 July 2020; accepted 19 November 2020; published online 26 February 2021

DOI: https://doi.org/10.20524/aog.2021.0601

\section{Introduction}

Nonalcoholic fatty liver disease (NAFLD) is known as one of the most common chronic liver diseases worldwide [1]. It encompasses the vast spectrum of liver injury from simple steatosis to steatohepatitis, cirrhosis, and rarely hepatocellular carcinoma $[1,2]$. The estimated prevalence ranges from 6.3$33 \%$ in the general population, increasing to over $50 \%$ among obese and diabetic patients [3,4]. The pathophysiology of NAFLD is multifactorial and characterized by hepatic fat accumulation, oxidative stress, lipid peroxidation, and mitochondrial dysfunction [5]. This process is supposed to be triggered by insulin resistance which not only increases de novo hepatic lipogenesis, but also causes lipolysis and elevation of free fatty acids' level that subsequently induce hepatic steatosis $[5,6]$. 
Cumulative evidence has shown that patients with NAFLD have a higher risk of cardiovascular events than the general population [7-9]. Inflammatory features of NAFLD mediates exacerbation of insulin resistance and also leads to atherogenic dyslipidemia; these factors are involved in the pathogenesis of cardiovascular diseases [10].

Lifestyle modification is deemed to be the most effective therapeutic modality for slowing down the progression of NAFLD $[11,12]$. In this way, dietary modifications and weight loss could reduce hepatic steatosis and improve disease activity $[13,14]$. However, there is inconsistent evidence regarding the effect of dietary interventions on cardio-metabolic risk factors, including insulin resistance and lipid profile in NAFLD. Mediterranean diet (MD) has been considered effective in controlling hepatic manifestations of NAFLD, though data on the impact of MD on dyslipidemia and insulin resistance indicators such as insulin level and homeostatic model assessment for insulin resistance (HOMA-IR) are conflicting [15]. On the other hand, multiple studies concentrated on low-fat/low-carbohydrate hypocaloric and ketogenic diets, although the effectiveness of these dietary patterns in improving hepatic and extra-hepatic complications of NAFLD is an area of dispute [14,16-18].

Recently, several systematic reviews have attempted to evaluate the effect of dietary modifications on the management of NAFLD although heterogeneity in the dietary pattern of the control groups limited the quality of the studies [15,19-22]. Therefore, in this systematic review and meta-analysis we aimed to summarize randomized controlled trials (RCTs) that assessed the effect of dietary interventions vs. controls, which has neither nutritional nor pharmacologic intervention on the cardio-metabolic risk factors, including lipid profile and insulin resistance in patients with NAFLD.

\section{Materials and methods}

This study was conducted in accordance with the systematic reviews and meta-analyses (PRISMA) guideline [23].

\section{Search strategy}

We systematically searched 2 electronic databases of PubMed-MEDLINE and Scopus-EMBASE to find relevant English published articles until January 2020. Keywords selected with 2 concepts of disease (NAFLD) and intervention (diet) (Appendix). Reviewers independently screened articles by title and abstract to find eligible studies and extracted data into a structured excel spreadsheet, and discrepancies were resolved by discussion.

\section{Eligibility criteria}

The entry requirement for the study was meeting the following criteria: (a) participants older than 18 years old with any sex or ethnic origin; (b) proven NAFLD or nonalcoholic steatohepatitis based on liver biopsy or imaging; (c) using dietary intervention; (d) designed base on RCT; and (e) reporting at least 1 of the lipid profile components (triglycerides [TG], total cholesterol [TC], high-density lipoprotein [HDL], low-density lipoprotein [LDL], and/or insulin resistance surrogate marker HOMA-IR) as main outcomes. The data of weight change was also extracted from the included articles. In the case of 2 studies with duplicate data, we only included that with more complete information and a higher quality (according to the modified version of Cochrane tool [24]). We also excluded articles with: (a) insufficient data; (b) inappropriate (dietary change in control group) or no control group; and (c) investigation the effects of other interventions simultaneously along with diet intervention.

\section{Data extraction}

We appraised the full text of the included articles and extracted following data: (a) general information including the name of first author, origin country, year of publication, and the number of participants; (b) lipid profile (TG, TC, HDL, LDL), insulin resistance surrogate marker HOMA-IR, and weight; (c) predefined criteria including age (lower or more than 50 years old), body mass index (BMI) 25-29.9 and $\geq 30 \mathrm{~kg} / \mathrm{m}^{2}$ interpreted as overweight and obese, respectively, and type of diet (MD [low-calorie] and standard [low-calorie or high-fiber]) [25].

\section{Risk of bias and quality assessment}

The risk of bias was assessed using the modified version of Cochrane tool [24]. Studies were evaluated in 6 domains: random sequence generation; allocation concealment; blinding; missing outcome data; selective outcome reporting; and other sources of bias. Each domain was judged as low, probably low, probably high, and high. Two reviewers independently assessed the risk of bias, and any disagreements were solved by discussion.

\section{Statistical analysis}

In the current study, we used the mean and standard deviation (SD) of post-intervention data to compute the metaanalysis. The following formulas were used to calculate SD if the studies reported another kind of variation of means:

$\mathrm{SD}$ from standard error $(\mathrm{SE})=\mathrm{SE}^{*} \sqrt{\mathrm{n}}$

SD from $95 \%$ confidence interval $(C I)=V_{n}$ (upper level [UL]-lower level [LL]/3.92)

$\mathrm{SD}$ from interquartile range $=\mathrm{UL}-\mathrm{LL} / 1.35$

If a study had reported baseline and change of variables, post-intervention SD could not be calculated. In this case, we considered the SD with $70 \%$ cumulative frequency for it.

Random-effect analysis was performed to calculate pooled weighted mean differences (WMD). We used the 95\%CIs to compare the results. If $95 \%$ CIs did not meet each other, the difference of WMDs was significant. We also considered 
P-heterogeneity (P-h) with the value of $<0.10$ as significant between-study heterogeneity. Subgroup analysis of the predefined criteria was conducted to find the potential source of heterogeneity and the effect of each subgroup on the overall WMD. Finally, Egger's test was applied to reveal potential publication bias. We used STATA, version 14.0 (Stata Corp, College Station, TX) for all statistical analyses.

\section{Results}

\section{Study selection}

Figure 1 briefly outlines the study selection process. 1976 unique articles were identified through PubMed and Scopus, of which 1966 articles were excluded after screening by title and abstract. The full texts of 11 relevant articles were reviewed to assess their eligibility. After excluding 6 articles due to implementing dietary intervention in control groups [17,26-29], and applying exercise intervention along with diet intervention in treatment group [30], only 5 studies met our inclusion criteria [16,31-34]. All cited references of the included studies and the relevant reviews were checked to find other potential eligible articles, but no other studies were included. Finally, 5 articles were used for data extraction and meta-analysis [16,31-34].

\section{Characteristics of the included studies}

Articles were published between 2015 and 2019. Two articles were performed in Italy $[33,34]$, and the other 3 were conducted in Iran [16], China [32], and Brazil [31]. The overall sample size was 190 ranging from 20 to 60 participants, with mean age ranging from $42-56.47$ years old. All the studies were done on both sexes.

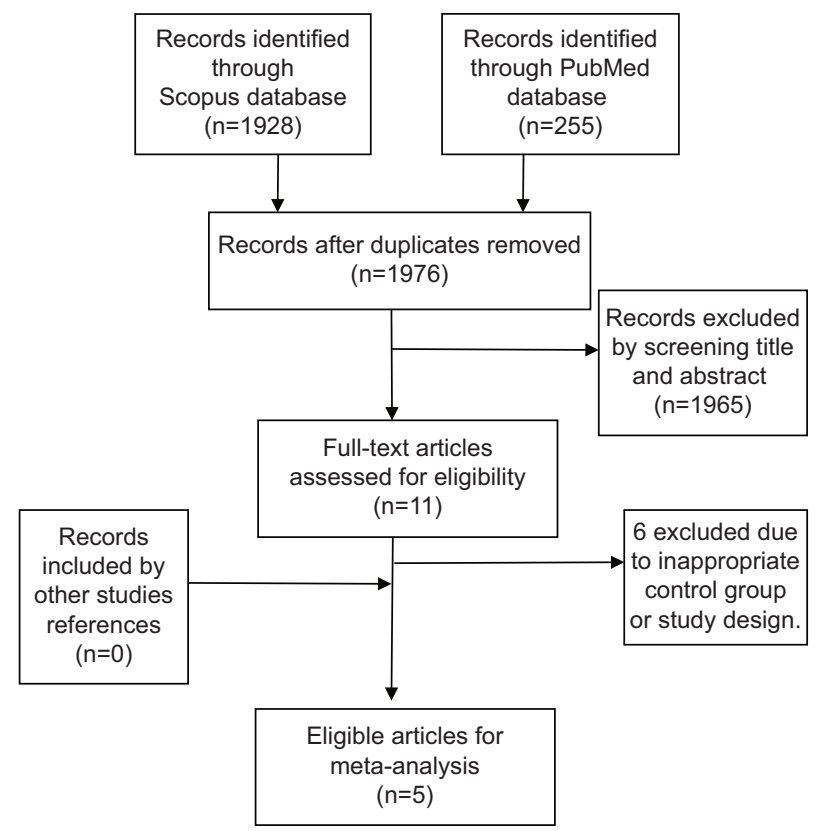

Figure 1 Flow diagram of study selection up to January 2020
Mean duration of intervention ranged from 3-8.6 months. Two articles had used low-calorie MD [33,34], 2 used standard lowcalorie diet [16,31], and 1 used a high-fiber diet [32]. Table 1 briefly shows the characteristics of the included studies.

Supplementary Table 1 summarizes the risk of bias assessment. Insufficient reporting of allocation concealment, lack of blinding, and missing outcomes were the main sources of limitations of the included studies.

\section{Effect of dietary intervention on TG level in patients with NAFLD}

Combining 5 effect sizes with 190 participants demonstrated that serum TG significantly decreased in response to dietary intervention ( $\mathrm{n}=5$, WMD $-38.50 \mathrm{mg} / \mathrm{dL}, 95 \% \mathrm{CI}-61.68$ to -15.31 ; $\mathrm{P}=0.001)$ with significant heterogeneity $(\mathrm{P}-\mathrm{h}=0.060)$ (Fig. 2; Table 2). According to the subgroup analysis, type and duration of intervention as well as the participants' BMI and age were the potential sources of heterogeneity (P-h>0.1) (Suppl. Table 2). Moreover, subgroup analysis revealed that results for dietary intervention in overweight participants $(\mathrm{P}=0.60)$ and using a high-fiber diet $(\mathrm{P}=0.67)$ were insignificant (Table 3$)$.

\section{Effect of dietary intervention on TC level in patients with NAFLD}

Pooling effect sizes from 4 studies showed a significant reduction in TC, without significant heterogeneity, in response to diet intervention $(\mathrm{n}=4, \mathrm{WMD}-18.70 \mathrm{mg} / \mathrm{dL}, 95 \% \mathrm{CI}-34.87$ to $-2.53 ; \mathrm{P}=0.023$ and $\mathrm{P}-\mathrm{h}=0.118$ ) (Fig. 3; Table 2). After applying subgroup analysis, results remained significant for obese patients $(\mathrm{n}=3$, WMD $-16.06 \mathrm{mg} / \mathrm{dL}, 95 \% \mathrm{CI}-39.01$ to 6.87; $\mathrm{P}=0.005)$, participants younger than 50 years old $(\mathrm{n}=2$, WMD $-23.20 \mathrm{mg} / \mathrm{dL}, 95 \% \mathrm{CI}-36.96$ to $-9.44 ; \mathrm{P}=0.001$ ), using other diets than MD ( $\mathrm{n}=2, \mathrm{WMD}=-23.20 \mathrm{mg} / \mathrm{dL}, 95 \% \mathrm{CI}-36.96$ to $-9.44 ; \mathrm{P}=0.001)$, and less than 3 months of intervention $(\mathrm{n}=2$, $\mathrm{WMD}=-23.20 \mathrm{mg} / \mathrm{dL}, 95 \% \mathrm{CI}-36.96$ to $-9.44 ; \mathrm{P}=0.001$ ) (Table 3 ).

\section{Effect of dietary intervention on HDL level in patients with NAFLD}

The pooled estimate from the 3 effect sizes with 120 participants showed no effect of diet on HDL level $(n=3$, WMD $-0.09 \mathrm{mg} / \mathrm{dL}, \quad 95 \% \mathrm{CI}-3.28$ to $3.10 ; \quad \mathrm{P}=0.955)$ (Suppl. Fig. 1, Table 2). There was no heterogeneity between studies $(\mathrm{P}-\mathrm{h}=0.43)$. Subgroup analysis also revealed no changes in the results for HDL (Table 3 ).

\section{Effect of dietary intervention on LDL level in patients with NAFLD}

According to data from 4 studies and 150 participants, there wasnosignificant changesfor serumlevel of LDL $(n=4$, WMD6.91 
Table 1 Characteristics of included studies

\begin{tabular}{|c|c|c|c|c|c|c|c|c|c|c|}
\hline \multirow[t]{2}{*}{ First author } & \multirow[t]{2}{*}{ Year } & \multirow[t]{2}{*}{ Country } & \multirow{2}{*}{$\begin{array}{l}\text { NAFLD } \\
\text { confirmation }\end{array}$} & \multirow[t]{2}{*}{ Quality } & \multirow{2}{*}{$\begin{array}{l}\text { Style of data } \\
\text { report }\end{array}$} & \multirow{2}{*}{$\begin{array}{l}\text { Interested } \\
\text { data report }\end{array}$} & \multirow{2}{*}{$\begin{array}{l}\text { Diet } \\
\text { macronutrient } \\
\text { distribution }\end{array}$} & \multirow{2}{*}{$\begin{array}{l}\text { Duration } \\
\text { (Months) }\end{array}$} & \multicolumn{2}{|c|}{ Sample size of groups } \\
\hline & & & & & & & & & Intervention & Control \\
\hline $\begin{array}{l}\text { de Faria } \\
\text { Ghetti [31] }\end{array}$ & 2019 & Brazil & Biopsy & High & $\begin{array}{l}\text { Before- After } \\
\text { Mean } \pm \text { SD }\end{array}$ & $\begin{array}{l}\text { HOMA-IR, } \\
\text { TG, TC, HDL, } \\
\text { LDL }\end{array}$ & $\begin{array}{l}\text { Standard, low- } \\
\text { calorie }\end{array}$ & 3 & 20 & 20 \\
\hline Asghari [16] & 2018 & Iran & US & High & $\begin{array}{l}\text { Before- After } \\
\text { Mean } \pm \text { SD }\end{array}$ & $\begin{array}{l}\text { HOMA-IR, } \\
\text { TG, TC, HDL, } \\
\text { LDL }\end{array}$ & $\begin{array}{l}\text { Standard, low- } \\
\text { calorie }\end{array}$ & 3 & 30 & 30 \\
\hline Cheng [32] & 2017 & China & H-MRS & High & $\begin{array}{l}\text { Before- After } \\
\text { Mean (CIs) }\end{array}$ & TG & $\begin{array}{l}\text { Modified, high } \\
\text { fiber }\end{array}$ & 8.6 & 22 & 18 \\
\hline $\begin{array}{l}\text { Abenavoli } \\
\text { [33] }\end{array}$ & 2017 & Italy & US & High & $\begin{array}{l}\text { Before- After } \\
\text { Mean (IQR) }\end{array}$ & $\begin{array}{l}\text { HOMA-IR, } \\
\text { TG, TC, LDL }\end{array}$ & $\begin{array}{l}\text { Mediterranean, } \\
\text { low-calorie }\end{array}$ & 6 & 20 & 10 \\
\hline $\begin{array}{l}\text { Abenavoli } \\
{[34]}\end{array}$ & 2015 & Italy & US & Unclear & $\begin{array}{l}\text { Before- After } \\
\text { Mean (IQR) }\end{array}$ & $\begin{array}{l}\text { HOMA-IR, } \\
\text { TG, TC, HDL, } \\
\text { LDL }\end{array}$ & $\begin{array}{l}\text { Mediterranean, } \\
\text { low-calorie }\end{array}$ & 6 & 10 & 10 \\
\hline
\end{tabular}

NAFLD, none alcoholic fatty liver disease; US, ultrasound; H-MRS, proton-magnetic resonance spectroscopy; SD, standard deviation; CI, confidence interval; $I Q R$, interquartile range; HOMA-IR, homeostatic model assessment for insulin resistance; TG, triglycerides; TC, total cholesterol; HDL, high-density lipoprotein cholesterol; LDL, low-density lipoprotein cholesterol

Table 2 Summary of results for cardio-metabolic risk factors

\begin{tabular}{|c|c|c|c|c|c|c|}
\hline Variable & $\mathrm{TG}(\mathrm{mg} / \mathrm{dL})$ & $\mathrm{TC}(\mathrm{mg} / \mathrm{dL})$ & HDL (mg/dL) & $\mathrm{LDL}(\mathrm{mg} / \mathrm{dL})$ & HOMA-IR & Weight $(\mathrm{Kg})$ \\
\hline Study & 5 & 4 & 3 & 4 & 4 & 5 \\
\hline Sample size & 190 & 150 & 120 & 150 & 150 & 190 \\
\hline WMD & -38.497 & -18.701 & -0.093 & 6.909 & -0.279 & -3.607 \\
\hline $95 \% \mathrm{CI}$ & $-61.685,-15.308$ & $-34.875,-2.528$ & $-3.284,3.098$ & $-20.254,34.072$ & $-1.015,0.457$ & $-7.254,0.041$ \\
\hline$P-\mathrm{H}$ & 0.060 & 0.118 & 0.432 & $<0.001$ & 0.954 & 0.325 \\
\hline$P-\mathrm{W}$ & 0.001 & 0.023 & 0.955 & 0.618 & 0.456 & 0.053 \\
\hline$P>|t|$ & 0.131 & 0.821 & 0.039 & 0.130 & 0.520 & 0.063 \\
\hline
\end{tabular}

TG, triglycerides; TC, total cholesterol; HDL, high-density lipoprotein cholesterol; LDL, low-density lipoprotein cholesterol; BMI, body mass index; HOMA-IR, homeostatic model assessment for insulin resistance

$W M D$, weighted mean difference; CIs, confidence intervals; $P$-W, P-Within test of WMD of subgroups with significance of $<0.05$ ); $P$ - $h$, P-heterogeneity (test of heterogeneity between studies with significance of $\langle 0.1$ ); $P>|t|$, test of small-study effects (with significance of $<0.05$ )

$\mathrm{mg} / \mathrm{dL}, 95 \% \mathrm{CI}-20.25$ to $34.07 ; \mathrm{P}=0.618$ ) (Suppl. Fig. 2, Table 2). However, between study heterogeneity was significant (P$\mathrm{h}=0.060$ ), and subgroup analysis demonstrated that type and duration of intervention and participant's age were the potential sources of heterogeneity ( $\mathrm{P}-\mathrm{h}>0.1$ ) (Suppl. Table 2). Subgroup analysis also revealed that the effect of diet in subgroups is completely reverse and significant; LDL level increased in the MD intervention ( $\mathrm{n}=2$, WMD $29.73 \mathrm{mg} / \mathrm{dL}, 95 \% \mathrm{CI}$ 13.82-45.65; $\mathrm{P}<0.001)$, more than 3 months of intervention $(\mathrm{n}=2$, WMD 29.73, 95\%CI 13.82-45.65; $\mathrm{P}<0.001$ ), and individuals over 50 years old ( $\mathrm{n}=2$, WMD $29.73 \mathrm{mg} / \mathrm{dL}, 95 \%$ CI 13.82-45.65; $\mathrm{P}<0.001)$, but decreased in the studies applying 3-month diet ( $\mathrm{n}=2$, WMD $-16.82 \mathrm{mg} / \mathrm{dL}, 95 \% \mathrm{CI}-29.44$ to $-4.19 ; \mathrm{P}=0.009$ ), other than MD ( $\mathrm{n}=2$, WMD $-16.82 \mathrm{mg} / \mathrm{dL}, 95 \% \mathrm{CI}-29.44$ to -4.19; $\mathrm{P}=0.009)$, and in participants younger than 50 years old $(\mathrm{n}=2, \mathrm{WMD}-16.82 \mathrm{mg} / \mathrm{dL}, 95 \% \mathrm{CI}-29.44$ to $-4.19 ; \mathrm{P}=0.001)$ (Table 3).

\section{Effect of dietary intervention on HOMA-IR level in patients} with NAFLD

There was no significant changes and heterogeneity for serum level of HOMA-IR ( $\mathrm{n}=4$, WMD $-0.279,95 \% \mathrm{CI}-1.01$ to $0.46 ; \mathrm{P}=0.456$ and $\mathrm{P}-\mathrm{h}=0.954$ ) according to data from 4 studies and 150 participants (Suppl. Fig. 3; Table 2). Subgroup analysis revealed no changes in the results for HOMA-IR (Table 3 ).

\section{Effect of dietary intervention on weight changes in patients with NAFLD}

All 5 included studies with 190 participants reported effect size for weight changes and our meta-analysis showed that dietary intervention was able to reduce weight, but marginally significantly $(\mathrm{n}=5$, WMD $-3.61 \mathrm{Kg}, 95 \% \mathrm{CI}-7.25$ to $0.04 ; \mathrm{P}=0.053$ ) (Suppl. Fig. 4; Table 2). There was no heterogeneity among the 


\begin{tabular}{|c|c|c|}
\hline Study & & $\%$ \\
\hline ID & WMD $(95 \% \mathrm{Cl})$ & Weight \\
\hline \multicolumn{3}{|l|}{ Other } \\
\hline Faria Ghetti (2019) & $-38.30(-83.62,7.02)$ & 15.34 \\
\hline Asghari (2018) & $-29.63(-72.00,12.74)$ & 16.56 \\
\hline Cheng (2017) & $8.86(-31.97,49.69)$ & 17.25 \\
\hline Subtotal $(I-$ squared $=26.5 \%, p=$ & $-18.56(-47.37,10.25)$ & 49.15 \\
\hline \multicolumn{3}{|l|}{ Mediterranean } \\
\hline Abenavoli (2017) & $-58.00(-83.25,-32.75)$ & 25.75 \\
\hline Abenavoli (2015) & $-57.00(-83.30,-30.70)$ & 25.10 \\
\hline $\begin{array}{l}\text { Subtotal }(\text { I-squared }=0.0 \% \\
p=0.957)\end{array}$ & $-57.52(-75.73,-39.31)$ & 50.85 \\
\hline $\begin{array}{l}\text { Overall (I-squared }=55.8 \% \\
p=0.060)\end{array}$ & \multirow{2}{*}{\multicolumn{2}{|c|}{$-38.50(-61.69,-15.31) 100.00$}} \\
\hline NOTE: Weights are from random & & \\
\hline $\begin{aligned} & 1 \\
&-83.6\end{aligned}$ & 83.6 & \\
\hline
\end{tabular}

Figure 2 Forest plot for the pooled weighted mean differences of diet interventions on the level of triglycerides based on random-effect model $W M D$, weighted mean difference; CI, confidence interval

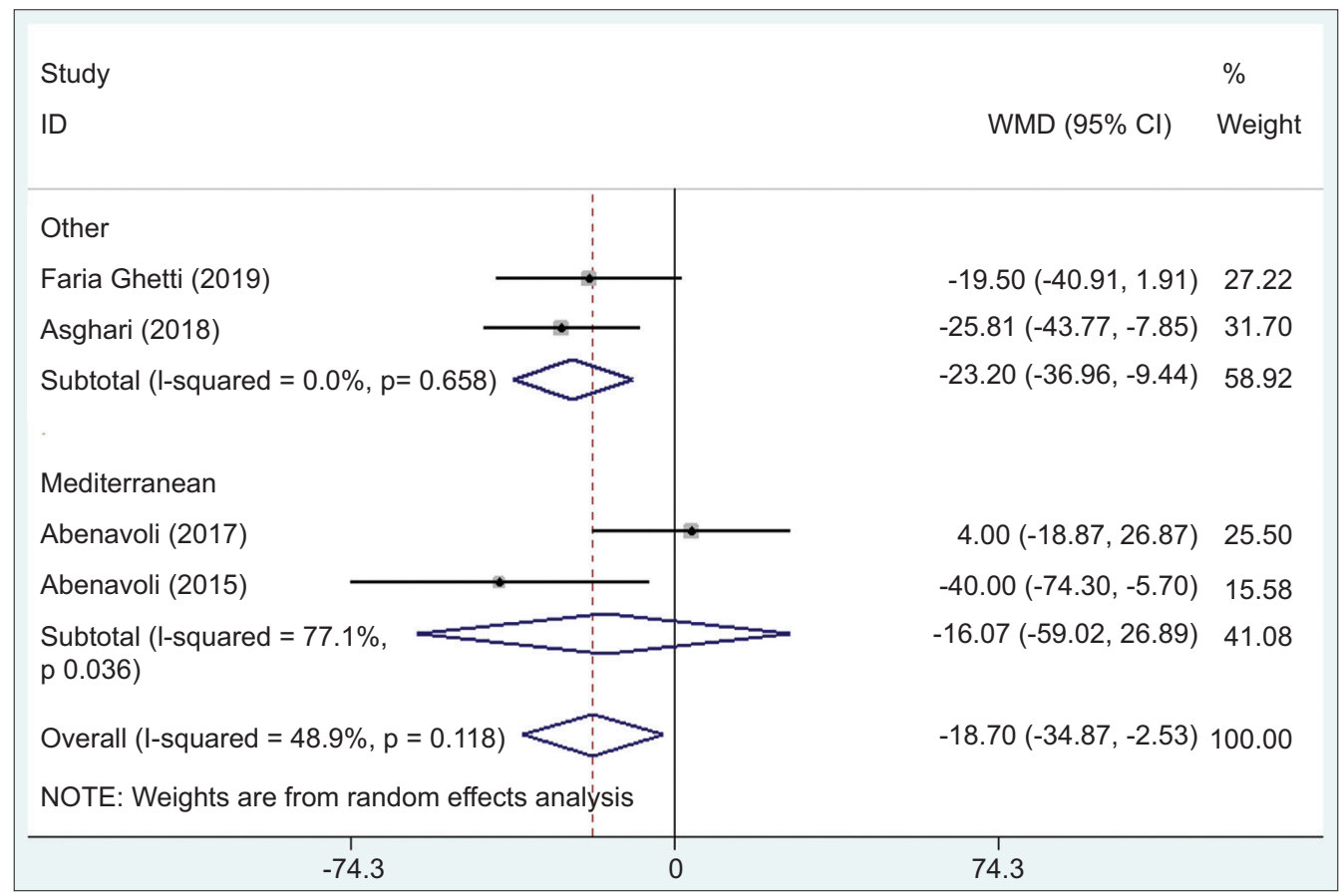

Figure 3 Forest plot for the pooled weighted mean differences of diet interventions on the level of total cholesterol based on random-effect model $W M D$, weighted mean difference; $C I$, confidence interval

studies $(\mathrm{P}-\mathrm{h}=0.325)$. After applying subgroup analysis, the weight reduction turned to significant in $\mathrm{MD}(\mathrm{n}=2$, WMD $-7.59 \mathrm{Kg}$, 95\%CI -13.53 to $-1.66 ; \mathrm{P}=0.012)$, and obese participants $(\mathrm{n}=3$, WMD $-7.83 \mathrm{Kg}$, 95\%CI -13.10 to $-2.56 ; \mathrm{P}=0.004$ ) (Table 3).

\section{Publication bias in the results}

Eager's test revealed publication bias only for HDL in response to dietary intervention $(\mathrm{P}=0.039)$ (Table 2$)$. 


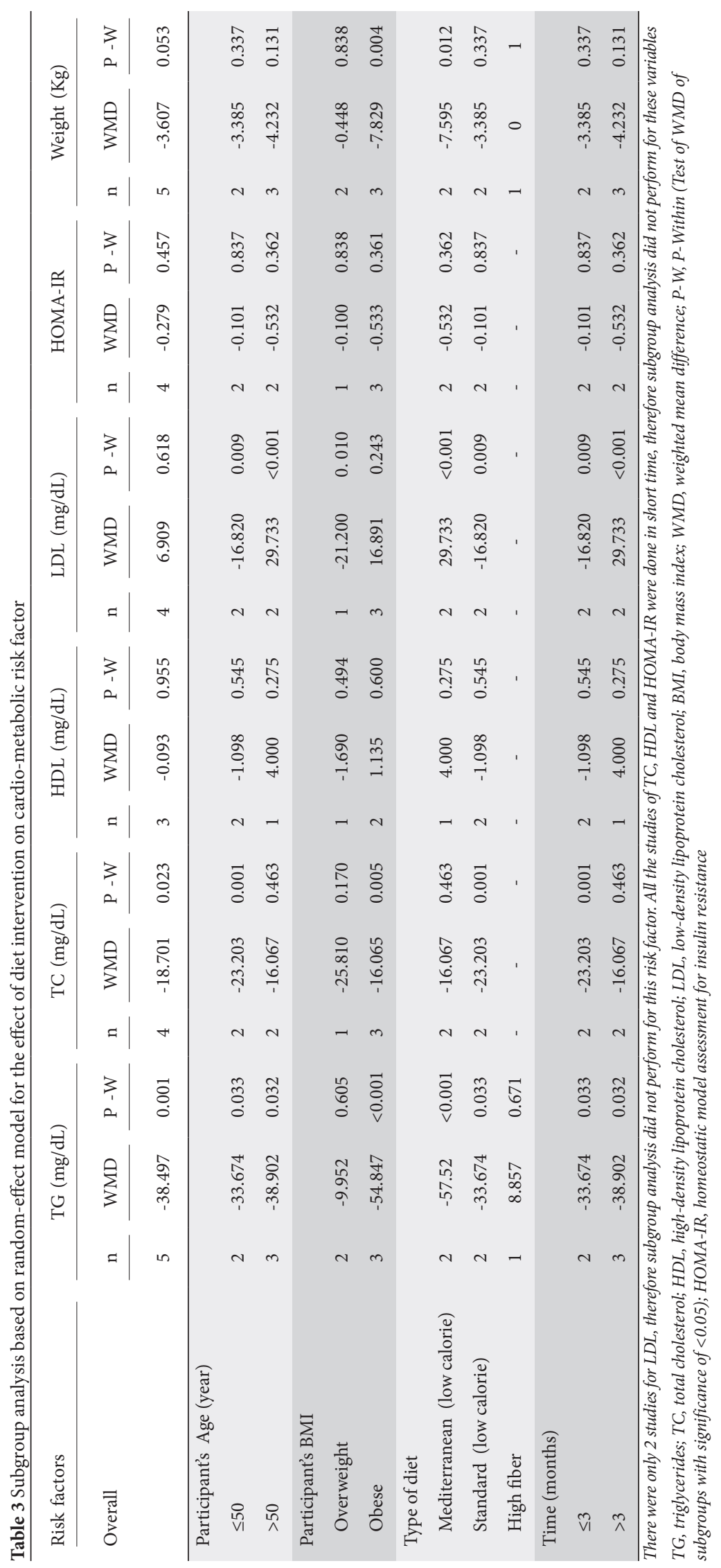




\section{Discussion}

In the present meta-analysis, we found that dietary intervention may reduce serum TG, TC, and weight in patients with NAFLD. There were no significant changes in LDL, HDL, and HOMAIR levels following the intervention. According to our subgroup analysis, even though dietary intervention across both age groups was effective in improving TG, patients younger than 50 years old were more likely to benefit from diet regarding the reduction in the TC level. Furthermore, compared to overweight individuals, obese patients most benefited from dietary modification to reduce TG and TC. MD was effective in reducing TG and weight, though hypocaloric diet decreased TC. Moreover, the result showed that dietary modification for 3 months can be as effective as a prolonged intervention in lowering TG and TC.

It is well-known that lifestyle modifications, including nutritional changes, exercise and weight loss are the cornerstone of NAFLD management $[11,12]$. While numerous types of dietary approaches have shown to be effective in improving liver steatosis, the optimal diet is still unclear. The included studies in our analysis applied MD $[33,34]$, calorie-restricted diet [16,31], and high-fiber diet [32]. Calorie restriction is a general dietary intervention in NAFLD that improves weight management and insulin sensitivity [14]. A meta-analysis of 3 randomized trials by Musso et al [13], emphasized the role of calorie restriction, regardless of macronutrient components, in improving TG and HOMA-IR. However, our results showed that standard hypocaloric diet was associated with a reduction in TC and had no effect on other cardio-metabolic risk factors.

According to the present meta-analysis, MD had a potential to reduce serum TG and weight in patients with NAFLD. $\mathrm{MD}$ is a less energy-dense diet, rich in monounsaturated fatty acids, omega-3 fatty acids, and antioxidants. These nutrients play an important role in modulating inflammatory cytokines, improving insulin sensitivity, and also regulating glucose and lipid metabolism [35]. A recent meta-analysis of 7 observational studies and 6 randomized trials reported that implementing MD was associated with reduction in TG, TC and HOMA-IR in NAFLD [21]. The effect of MD on improving TG, TC and HOMAIR in NAFLD patients has been highlighted in other systematic reviews as well $[20,22]$. The aforementioned systematic reviews included trials in which patients in the control groups had some dietary modifications after the enrolment to the study compared to their baseline diet, while we included, as far as possible, RCTs that reported no dietary changes in the control groups after the study enrolment. Therefore, differences in inclusion criteria would be the main reason of conflict between their results and ours.

According to our data, the LDL level did not improve in response to dietary intervention, however, $\mathrm{MD}$ might increase it. This finding is inconsistent with previous metaanalyses in which adherence to the MD intermediated the LDL level [36] or MD intervention had no beneficial effect on the LDL level $[21,22]$. In the present meta-analysis, the data on $\mathrm{LDL}$ in response to MD was only extracted from 2 studies done by Abenavoli et al in which LDL level improved after both MD and control intervention with a 2-fold greater reduction in the control groups $[33,34]$. Since, we performed analysis on post- intervention extracted data, the results related to these 2 RCTs, including the effects of MD intervention and a longer than 3 months period, showed an increase in the LDL level.

One of the included studies in this meta-analysis implemented a high-fiber diet in the management of NAFLD [32]. We extracted data on serum TG level from this study which demonstrated no significant effect of high-fiber diet on TG level. Dietary fiber regulates gut microbiota and prevents translocation of pathogenic bacteria to the systemic circulation [37]; pathogenic bacteria induce systemic inflammatory responses and lead to insulin resistance [38]. Moreover, a review of recent RCTs investigating the relationship between diet high in fiber, microbiota and cardio-metabolic risk factors, indicated that high-fiber dietinduced metabolic responses were associated with individual microbiota composition and diversity and abundance of specific bacteria [39].

Several limitations would afflict the results of this study. Primarily, there is serious concern regarding the risk of bias of the included studies. Second, inconsistency in the results of TG and LDL would lower the certainty of the estimated effects for these outcomes. Third, the number of the included studies was relatively low with small sample sizes which limited the precision of the estimated effects. Forth, dietary compositions in the included studies were variable that would question the accuracy of our categorization of dietary interventions and prevent from clear judgment about the association of dietary pattern and outcomes of interest. Fifth, a number of the included studies enrolled NAFLD subjects with normal cardio-metabolic variables at baseline that could intervene in the measured effect size for dietary intervention.

According to this systematic review, dietary modifications may improve serum TG, TC in NAFLD. However, the effectiveness of diet directly relates to the nutritional components, intervention follow up, as well as patients' age and BMI. Although our results showed that NAFLD patients were likely to benefit of dietary modification, both clinical and statistically significance indicated that there is more benefit to intermediate TG, TC and LDL from low-calorie standard diet intervention with a shorter follow up than 3 months, especially in young and obese patients. The results also showed marginal statistically significance for weight reduction in response to dietary intervention, however, the WMD of approximately 0.5 $1 \mathrm{Kg}$ achieved over trial periods, over 3-6 months, is minimal and therefore unlikely to be of clinical significance. RCTs with larger sample sizes and a longer duration of intervention are warranted to validate these findings.

In conclusion, this systematic review highlighted the benefit of nutritional modification in improving dyslipidemia in patients with NAFLD. Moreover, our findings emphasize the gap in identification of optimal diet and potential need for implementing individualized dietary approaches in NAFLD.

\section{Acknowledgment}

The authors would like to thank Misciagna et al [28] for providing additional data upon request. 


\section{Summary Box}

\section{What is already known:}

- Patients with nonalcoholic fatty liver disease (NAFLD) have a higher risk of cardiovascular events than the general population

- Lifestyle modifications, including nutritional changes, exercise, and weight loss are the cornerstone of NAFLD management

- Adherence to the Mediterranean diet might intermediate the low-density lipoprotein (LDL) level in patients with NAFLD

\section{What the new findings are:}

- Nutritional modifications may improve serum triglycerides (TG) and total cholesterol (TC) in patients with NAFLD

- There is more benefit to intermediate TG, TC and LDL from low-calorie standard diet intervention with a shorter than 3 months follow up, especially in young and obese patients

- Our findings emphasize the gap in the identification of optimal diet and the potential need for implementing individualized dietary approaches in patients with NAFLD

\section{References}

1. Bellentani S. The epidemiology of non-alcoholic fatty liver disease. Liver Int 2017;37(Suppl 1):81-84.

2. Adams LA, Lymp JF, St Sauver J, et al. The natural history of nonalcoholic fatty liver disease: a population-based cohort study. Gastroenterology 2005;129:113-121.

3. Vernon G, Baranova A, Younossi Z.M. Systematic review: the epidemiology and natural history of non-alcoholic fatty liver disease and non-alcoholic steatohepatitis in adults. Aliment Pharmacol Ther 2011;34:274-285.

4. Chalasani N, Younossi Z, Lavine J.E, et al. The diagnosis and management of non-alcoholic fatty liver disease: practice Guideline by the American Association for the Study of Liver Diseases, American College of Gastroenterology, and the American Gastroenterological Association. Hepatology 2012;55:2005-2023.

5. Day CP. Pathogenesis of steatohepatitis. Best Pract Res Clin Gastroenterol 2002;16:663-678.

6. Liu W, Baker R.D, Bhatia T, et al. Pathogenesis of nonalcoholic steatohepatitis. Cell Mol Life Sci 2016:73:1969-1987.

7. Treeprasertsuk S, Leverage S, Adams LA, et al. The Framingham risk score and heart disease in nonalcoholic fatty liver disease. Liver Int 2012;32:945-950.

8. Pisto P, Santaniemi M, Bloigu R, et al. Fatty liver predicts the risk for cardiovascular events in middle-aged population: a populationbased cohort study. BMJ Open 2014;4:e004973.

9. Hamaguchi M, Kojima T, Takeda N, et al. Nonalcoholic fatty liver disease is a novel predictor of cardiovascular disease. World $J$ Gastroenterol 2007;13:1579-1584.
10. Targher G, Day CP, Bonora E. Risk of cardiovascular disease in patients with nonalcoholic fatty liver disease. $N$ Engl J Med 2010;363:1341-1350.

11. EASL-EASD-EASO. Clinical practice guidelines for the management of non-alcoholic fatty liver disease. Obes Facts 2016;9:65-90.

12. Chalasani N, Younossi Z, Lavine JE, et al. The diagnosis and management of nonalcoholic fatty liver disease: practice guidance from the american association for the study of liver diseases. Hepatology 2018;67:328-357.

13. Musso G, Cassader M, Rosina F, et al. Impact of current treatments on liver disease, glucose metabolism and cardiovascular risk in non-alcoholic fatty liver disease (NAFLD): a systematic review and meta-analysis of randomised trials. Diabetologia 2012;55:885-904.

14. Haufe S, Engeli S, Kast P, et al. Randomized comparison of reduced fat and reduced carbohydrate hypocaloric diets on intrahepatic fat in overweight and obese human subjects. Hepatology 2011;53:1504-1514.

15. Moosavian SP, Arab A, Paknahad Z. The effect of a Mediterranean diet on metabolic parameters in patients with non-alcoholic fatty liver disease: a systematic review of randomized controlled trials. Clin Nutr ESPEN 2020;35:40-46.

16. Asghari S, Asghari-Jafarabadi M, Somi MH, et al. Comparison of calorie-restricted diet and resveratrol supplementation on anthropometric indices, metabolic parameters, and serum sirtuin-1 levels in patients with nonalcoholic fatty liver disease: a randomized controlled clinical trial. J Am Coll Nutr 2018;37:223-233.

17. Properzi C, O'Sullivan TA, Sherriff JL, et al. Ad libitum Mediterranean and low-fat diets both significantly reduce hepatic steatosis: a randomized controlled trial. Hepatology 2018;68:1741-1754.

18. Kirk E, Reeds DN, Finck BN, et al. Dietary fat and carbohydrates differentially alter insulin sensitivity during caloric restriction. Gastroenterology 2009;136:1552-1560.

19. Parker A, Kim Y. The effect of low glycemic index and glycemic load diets on hepatic fat mass, insulin resistance, and blood lipid panels in individuals with nonalcoholic fatty liver disease. Metab Syndr Relat Disord 2019;17:389-396.

20. Saeed N, Nadeau B, Shannon C, et al. Evaluation of dietary approaches for the treatment of non-alcoholic fatty liver disease: a systematic review. Nutrients 2019;11:3064.

21. Akhlaghi M, Ghasemi-Nasab M, Riasatian M. Mediterranean diet for patients with non-alcoholic fatty liver disease, a systematic review and meta-analysis of observational and clinical investigations. J Diabetes Metab Disord 2020;19:575-584.

22. Asbaghi O, Choghakhori R, Ashtary-Larky D, et al. Effects of the Mediterranean diet on cardiovascular risk factors in non-alcoholic fatty liver disease patients: a systematic review and meta-analysis. Clin Nutr ESPEN 2020;37:148-156.

23. Moher D, Liberati A, Tetzlaff J, et al. Preferred reporting items for systematic reviews and meta-analyses: the PRISMA statement. PLoS Med 2009;6:e1000097.

24. Higgins J.P.T, Altman D.G, Gøtzsche P.C, et al. The Cochrane Collaboration's tool for assessing risk of bias in randomised trials. BMJ 2011;343:d5928.

25. Ardern C.I, Janssen I, Ross R, et al. Development of health-related waist circumference thresholds within BMI categories. Obes Res 2004;12:1094-1103.

26. Ryan MC, Itsiopoulos C, Thodis T, et al. The Mediterranean diet improves hepatic steatosis and insulin sensitivity in individuals with non-alcoholic fatty liver disease. J Hepatol 2013;59:138-143.

27. Katsagoni C.N, Papatheodoridis G.V, Ioannidou P, et al. Improvements in clinical characteristics of patients with nonalcoholic fatty liver disease, after an intervention based on the Mediterranean lifestyle: a randomised controlled clinical trial. $\mathrm{Br}$ J Nutr 2018;120:164-175.

28. Misciagna G, Del Pilar Díaz M, Caramia D.V, et al. Effect of a low 
glycemic index Mediterranean diet on non-alcoholic fatty liver disease. a randomized controlled clinici trial. J Nutr Health Aging 2017;21:404-412.

29. Marin-Alejandre B.A, Abete I, Cantero I, et al. The metabolic and hepatic impact of two personalized dietary strategies in subjects with obesity and nonalcoholic fatty liver disease: the fatty liver in obesity (FLiO) randomized controlled trial. Nutrients 2019;11:2543.

30. Ueno T, Sugawara H, Sujaku K, et al. Therapeutic effects of restricted diet and exercise in obese patients with fatty liver. $J$ Hepatol 1997;27:103-107.

31. Ghetti FF, De Oliveira DG, De Oliveira JM, et al. Effects of dietary intervention on gut microbiota and metabolic-nutritional profile of outpatients with non-alcoholic steatohepatitis: a randomized clinical trial. J Gastrointestin Liver Dis 2019;28:279-287.

32. Cheng S, Ge J, Zhao C, et al. Effect of aerobic exercise and diet on liver fat in pre-diabetic patients with non-alcoholic-fatty-liverdisease: a randomized controlled trial. Sci Rep 2017;7:15952.

33. Abenavoli L, Greco M, Milic N, et al. Effect of Mediterranean diet and antioxidant formulation in non-alcoholic fatty liver disease: a randomized study. Nutrients 2017;9:870.

34. Abenavoli L, Greco M, Nazionale I, et al. Effects of Mediterranean diet supplemented with silybin-vitamin E-phospholipid complex in overweight patients with non-alcoholic fatty liver disease. Expert Rev Gastroenterol Hepatol 2015;9:519-527.

35. Godos J, Federico A, Dallio M, et al. Mediterranean diet and nonalcoholic fatty liver disease: molecular mechanisms of protection. Int J Food Sci Nutr 2017;68:18-27.

36. Tsartsou E, Proutsos N, Castana E, et al. Network meta-analysis of metabolic effects of olive-oil in humans shows the importance of olive oil consumption with moderate polyphenol levels as part of the mediterranean diet. Front Nutr 2019;12:6.

37. Federico A, Dallio M, Godos J, et al. Targeting gut-liver axis for the treatment of nonalcoholic steatohepatitis: translational and clinical evidence. Transl Res 2016;167:116-124.

38. Schnabl B, Brenner D.A. Interactions between the intestinal microbiome and liver diseases. Gastroenterology 2014;146:1513-1524.

39. Schnabl B, Brenner D.A. Dietary fiber, gut microbiota, and metabolic regulation-current status in human randomized trials. Nutrients 2020;12:859. 


\section{Supplementary material}

Appendix Search strategy

PubMed: limited to clinical trial, human, English

\begin{tabular}{|c|c|c|c|}
\hline PubMed & $\begin{array}{l}\text { Nonalcoholic fatty liver disease } \\
\text { (Title) }\end{array}$ & $\begin{array}{l}\text { Weight loss intervention } \\
\text { (Title \& Abstract) }\end{array}$ & Study \\
\hline $\mathrm{MeSH}$ & Non-alcoholic Fatty Liver Disease & $\begin{array}{l}\text { Diet, Carbohydrate-Restricted } \\
\text { Diet, Mediterranean } \\
\text { Diet, Fat-Restricted } \\
\text { Diet, Vegetarian } \\
\text { Diet, Reducing } \\
\text { Diet Therapy } \\
\text { Life Style } \\
\text { Weight Reduction Program }\end{array}$ & 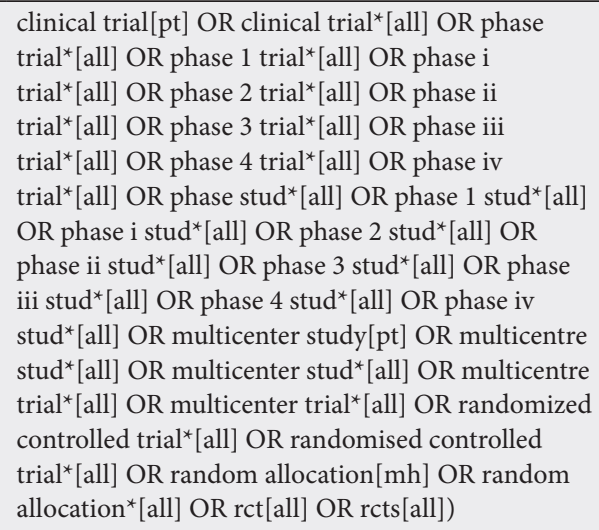 \\
\hline $\begin{array}{l}\text { Text } \\
\text { words }\end{array}$ & $\begin{array}{l}\text { "nonalcoholic fatty liver" } \\
\text { "non-alcoholic fatty liver" } \\
\text { "NAFLD" } \\
\text { "non-alcoholic steatohepatitis" } \\
\text { "nonalcoholic steatohepatitis" } \\
\text { "NASH" } \\
\text { "Steatosis" } \\
\text { "Steatohepatitis" } \\
\text { "hepatic steatosis" } \\
\text { "liver fat" } \\
\text { "hepatic fat" } \\
\text { "non-alcoholic" }\end{array}$ & $\begin{array}{l}\text { "Dietary intervention" } \\
\text { "Diet" } \\
\text { "Dietary" } \\
\text { "Diet"” } \\
\text { "lifestyle modification" } \\
\text { "lifestyle intervention" } \\
\text { "lifestyle" }\end{array}$ & \\
\hline & 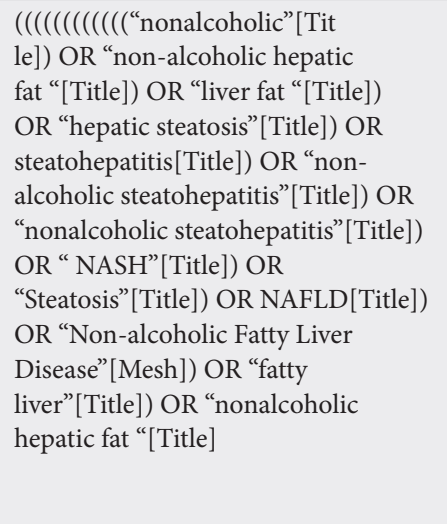 & 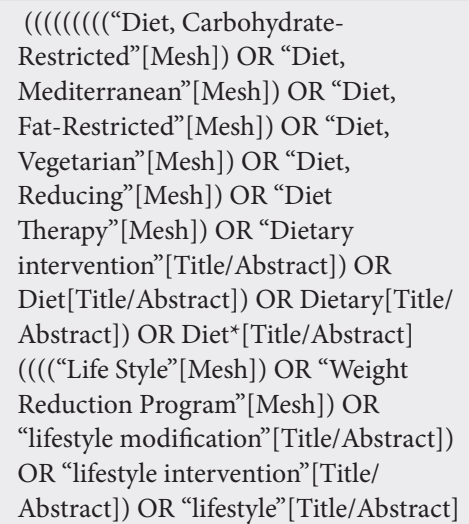 & \\
\hline $\begin{array}{l}\text { Result } \\
\mathbf{2 5 5} \\
\text { (up to } \\
\text { January } \\
\text { 2020) }\end{array}$ & \multicolumn{3}{|c|}{ 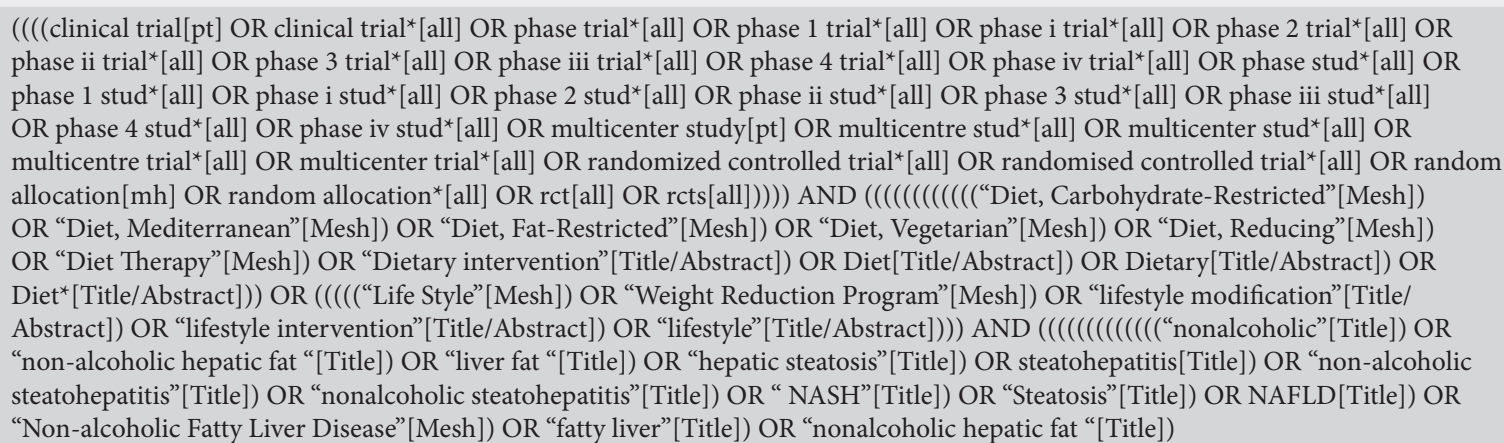 } \\
\hline
\end{tabular}


Scopus: limited to article and English

\begin{tabular}{|c|c|c|c|}
\hline Scopus & Nonalcoholic fatty liver diseas (Article title) & $\begin{array}{l}\text { Weight loss intervention (Title \& } \\
\text { Abstract) }\end{array}$ & Study \\
\hline & $\begin{array}{l}\text { "nonalcoholic fatty liver" } \\
\text { "non-alcoholic fatty liver" } \\
\text { "NAFLD" } \\
\text { "non-alcoholic steatohepatitis" } \\
\text { "nonalcoholic steatohepatitis" } \\
\text { "NASH" } \\
\text { "Steatosis" } \\
\text { "Steatohepatitis" } \\
\text { "hepatic steatosis" } \\
\text { "liver fat" } \\
\text { "hepatic fat" } \\
\text { "non-alcoholic" } \\
\text { "nonalcoholic" }\end{array}$ & $\begin{array}{l}\text { "Carbohydrate-Restricted diet" } \\
\text { "Mediterranean diet" } \\
\text { "Fat-Restricted diet" } \\
\text { "Vegetarian diet" } \\
\text { "Reducing diet" } \\
\text { "Diet Therapy" } \\
\text { "Dietary intervention" } \\
\text { "Dietary intervention" } \\
\text { "Diet" } \\
\text { "Dietary" } \\
\text { "Diet»" } \\
\text { "lifestyle modification" } \\
\text { "lifestyle intervention" } \\
\text { "lifestyle" } \\
\text { "Life Style" } \\
\text { "Weight Reduction Program" }\end{array}$ & $\begin{array}{l}\text { 1. Randomized controlled } \\
\text { trial } \\
\text { 2. Controlled clinical trial } \\
\text { 3. Randomized } \\
\text { 4. Randomly } \\
\text { 5. Trial } \\
\text { 6. Groups } \\
\text { 7. \#1 OR \#2 OR \#3 OR \#4 } \\
\text { OR \#5 OR \#6 } \\
\text { 8. Animals AND NOT } \\
\text { humans } \\
\text { \# AND NOT \#8 }\end{array}$ \\
\hline & $\begin{array}{l}\text { ( TITLE ( "nonalcoholic") OR TITLE ( "nonalcoholic fatty } \\
\text { liver") OR TITLE ("non-alcoholic fatty liver") OR TITLE } \\
\text { ("NAFLD") OR TITLE ("non-alcoholic") OR TITLE } \\
\text { ("hepatic fat") OR TITLE ("liver fat") OR TITLE } \\
\text { ("hepatic steatosis") OR TITLE ("Steatohepatitis") OR } \\
\text { TITLE ("Steatosis") OR TITLE ( "NASH") OR TITLE } \\
\text { ("nonalcoholic steatohepatitis") OR TITLE ( "non-alcoholic } \\
\text { steatohepatitis") ) }\end{array}$ & 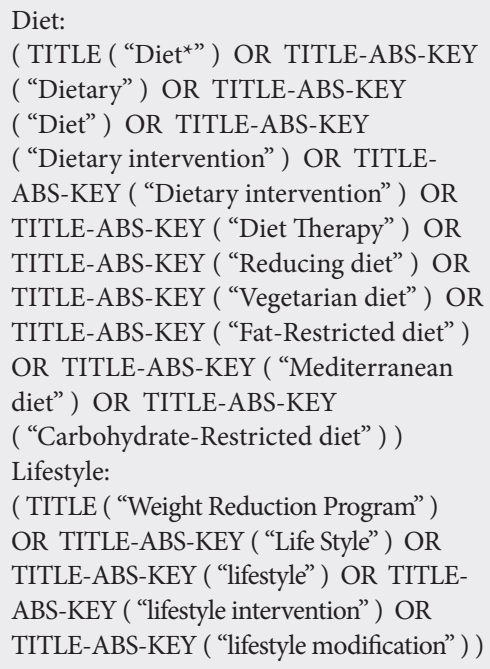 & $\begin{array}{l}\text { ( ( ( TITLE-ABS-KEY } \\
\text { ( "Randomized controlled } \\
\text { trial”) ) OR ( TITLE- } \\
\text { ABS-KEY ( "Controlled } \\
\text { clinical trial”) ) OR } \\
\text { ( TITLE-ABS-KEY } \\
\text { ( "Randomized") ) OR } \\
\text { ( TITLE-ABS-KEY } \\
\text { ( "Randomly") ) OR } \\
\text { ( TITLE-ABS-KEY } \\
\text { ( "Trial”) ) OR ( TITLE- } \\
\text { ABS-KEY ( "Groups") ) ) } \\
\text { AND NOT ( ( TITLE- } \\
\text { ABS-KEY ( "animal”) ) } \\
\text { AND NOT ( TITLE-ABS- } \\
\text { KEY ( "humans") ) ) ) }\end{array}$ \\
\hline $\begin{array}{l}\mathbf{1 9 2 8} \\
\text { (up to } \\
\text { January } \\
2020 \text { ) }\end{array}$ & \multicolumn{3}{|c|}{ 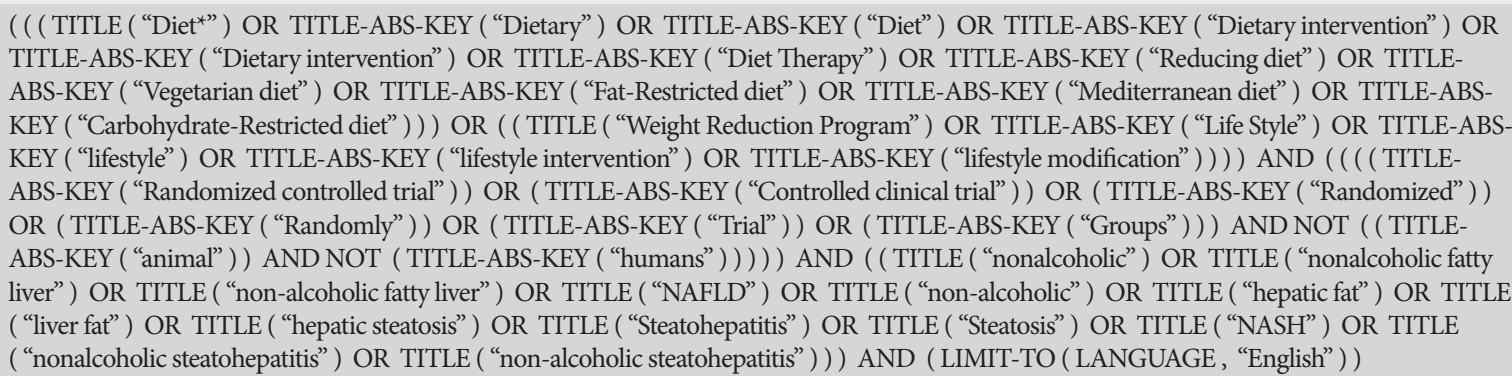 } \\
\hline
\end{tabular}


Supplementary Table 1 Risk of bias assessment of included studies

\begin{tabular}{|c|c|c|c|c|c|c|c|}
\hline First author & $\begin{array}{l}\text { Random } \\
\text { sequence } \\
\text { generation }\end{array}$ & $\begin{array}{l}\text { Allocation } \\
\text { concealment }\end{array}$ & $\begin{array}{l}\text { Blinding of } \\
\text { participants } \\
\text { and personnel }\end{array}$ & $\begin{array}{l}\text { Blinding of } \\
\text { outcome } \\
\text { assessor }\end{array}$ & $\begin{array}{l}\text { Missing } \\
\text { outcome } \\
\text { data }\end{array}$ & $\begin{array}{l}\text { Selective } \\
\text { outcome } \\
\text { reporting }\end{array}$ & $\begin{array}{l}\text { Other } \\
\text { risk of } \\
\text { bias }\end{array}$ \\
\hline de Faria Ghetti 2019 [31]* & Low & $\begin{array}{l}\text { Probably } \\
\text { High }\end{array}$ & High & High & Low & Low & Low \\
\hline Asghari $2018[16]^{*}$ & Low & $\begin{array}{l}\text { Probably } \\
\text { high }\end{array}$ & High & High & High & Low & Low \\
\hline Cheng $2017[32]^{*}$ & Low & Low & High & Low & High & Low & Low \\
\hline Abenavoli $2017[33]^{*}$ & $\begin{array}{l}\text { Probably } \\
\text { low }\end{array}$ & $\begin{array}{l}\text { Probably } \\
\text { high }\end{array}$ & Probably high & $\begin{array}{l}\text { Probably } \\
\text { high }\end{array}$ & Low & Low & $\begin{array}{l}\text { Probably } \\
\text { high } ¥\end{array}$ \\
\hline Abenavoli $2015[34]^{*}$ & $\begin{array}{l}\text { Probably } \\
\text { low }\end{array}$ & $\begin{array}{l}\text { Probably } \\
\text { high }\end{array}$ & Probably high & $\begin{array}{l}\text { Probably } \\
\text { high }\end{array}$ & Low & Low & $\begin{array}{l}\text { Probably } \\
\text { high } ¥\end{array}$ \\
\hline
\end{tabular}

${ }^{*}$ Risk of bias were the same across outcomes of interest within each study

$¥$ Baseline imbalance

Supplementary Table 2 Subgroup analysis based on random-effect models to find the potential source of heterogeneity

\begin{tabular}{|c|c|c|c|c|c|c|}
\hline \multirow{2}{*}{$\begin{array}{l}\text { Intervention } \\
\text { Overall }\end{array}$} & \multicolumn{3}{|c|}{ Diet on TG } & \multicolumn{3}{|c|}{ Diet on LDL } \\
\hline & $\mathrm{n}$ & $I^{2}(\%)$ & P-h & $\mathrm{n}$ & $I^{2}(\%)$ & P-h \\
\hline & 5 & 55.8 & 0.060 & 4 & 86.2 & $<0.001$ \\
\hline \multicolumn{7}{|l|}{ Study quality } \\
\hline High & 4 & 60.6 & 0.055 & 3 & 83.3 & 0.003 \\
\hline Unclear & 1 & - & - & 1 & - & - \\
\hline \multicolumn{7}{|l|}{ Participants' age (year) } \\
\hline$\leq 50$ & 2 & 0 & 0 & 2 & 0 & 0.400 \\
\hline$>50$ & 3 & 76.4 & 76.4 & 2 & 0 & 0.369 \\
\hline \multicolumn{7}{|l|}{ Participant's BMI } \\
\hline Overweight & 2 & 39.2 & 0.200 & 1 & - & - \\
\hline Obese & 3 & 0 & 0.742 & 3 & 86.2 & 0.006 \\
\hline \multicolumn{7}{|l|}{ Type of diet } \\
\hline Mediterranean (low calorie) & 2 & 0 & $<0.001$ & 2 & 0 & 0.369 \\
\hline Standard (low calorie) & 2 & 0 & $<0.001$ & 2 & 0 & 0.400 \\
\hline High fiber & 1 & - & - & 0 & - & - \\
\hline \multicolumn{7}{|l|}{ Time (months) } \\
\hline$\leq 3$ & 2 & 0 & 0.784 & 2 & 0 & 0.400 \\
\hline$>3$ & 3 & 76.4 & 0.014 & 2 & 0 & 0.369 \\
\hline
\end{tabular}

$I^{2}$ : the variation in weighted mean difference (WMD) attributable to heterogeneity; $P$ - $h, P$ - heterogeneity (test of heterogeneity between studies with significance of $\left.<0.1\right)$ ${ }^{*}$ After applying subgroup analysis, if heterogeneity turns to insignificance, that criterion is considered as a potential source of heterogeneity

$T G$, triglycerides; LDL, low-density lipoprotein cholesterol; BMI, body mass index 


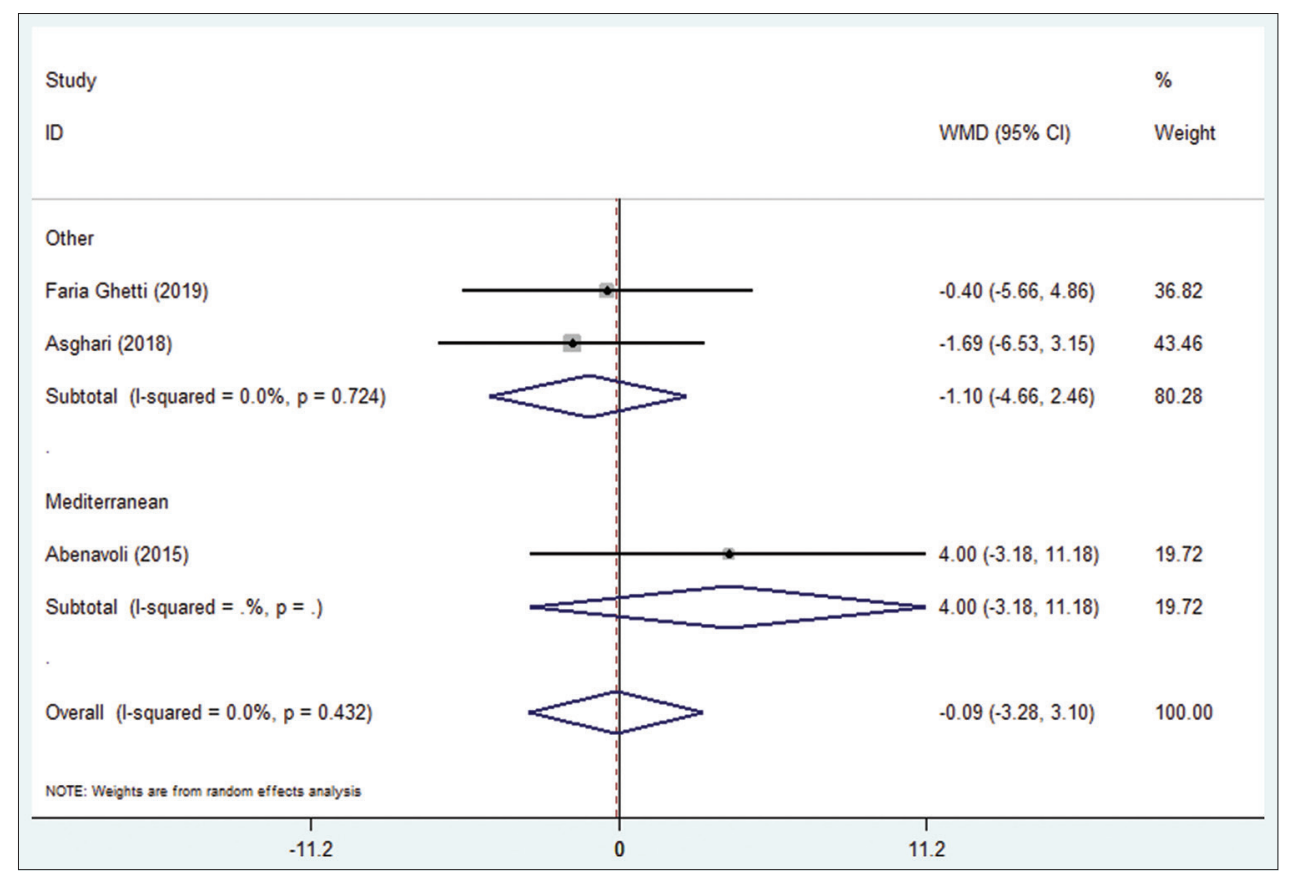

Supplementary Figure 1 Forest plot for the pooled weighted mean differences of diet interventions on the level of high-density lipoprotein cholesterol based on random-effect model WMD, weighted mean difference; $C I$, confidence interval

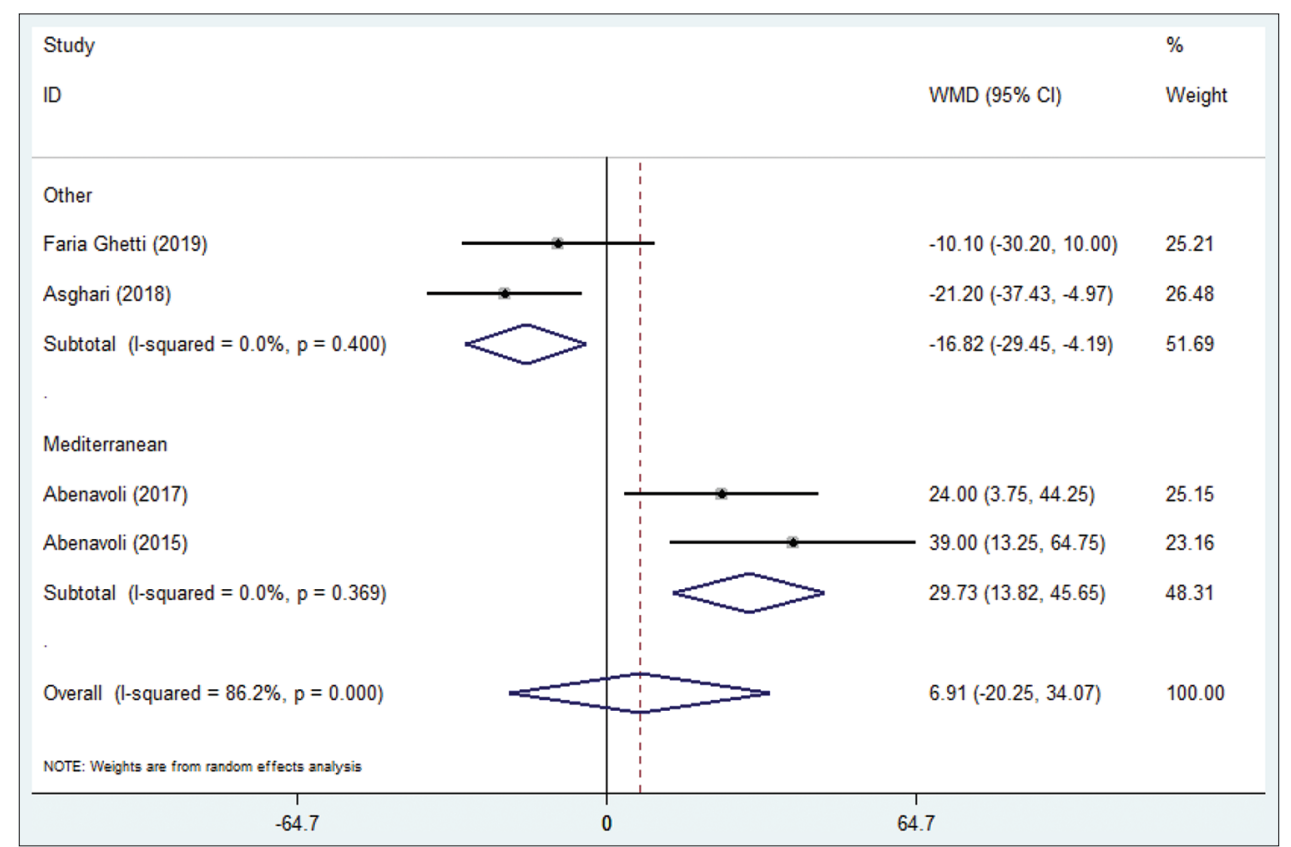

Supplementary Figure 2 Forest plot for the pooled weighted mean differences of diet interventions on the level of low-density lipoprotein cholesterol based on random-effect model

$W M D$, weighted mean difference; CI, confidence interval 


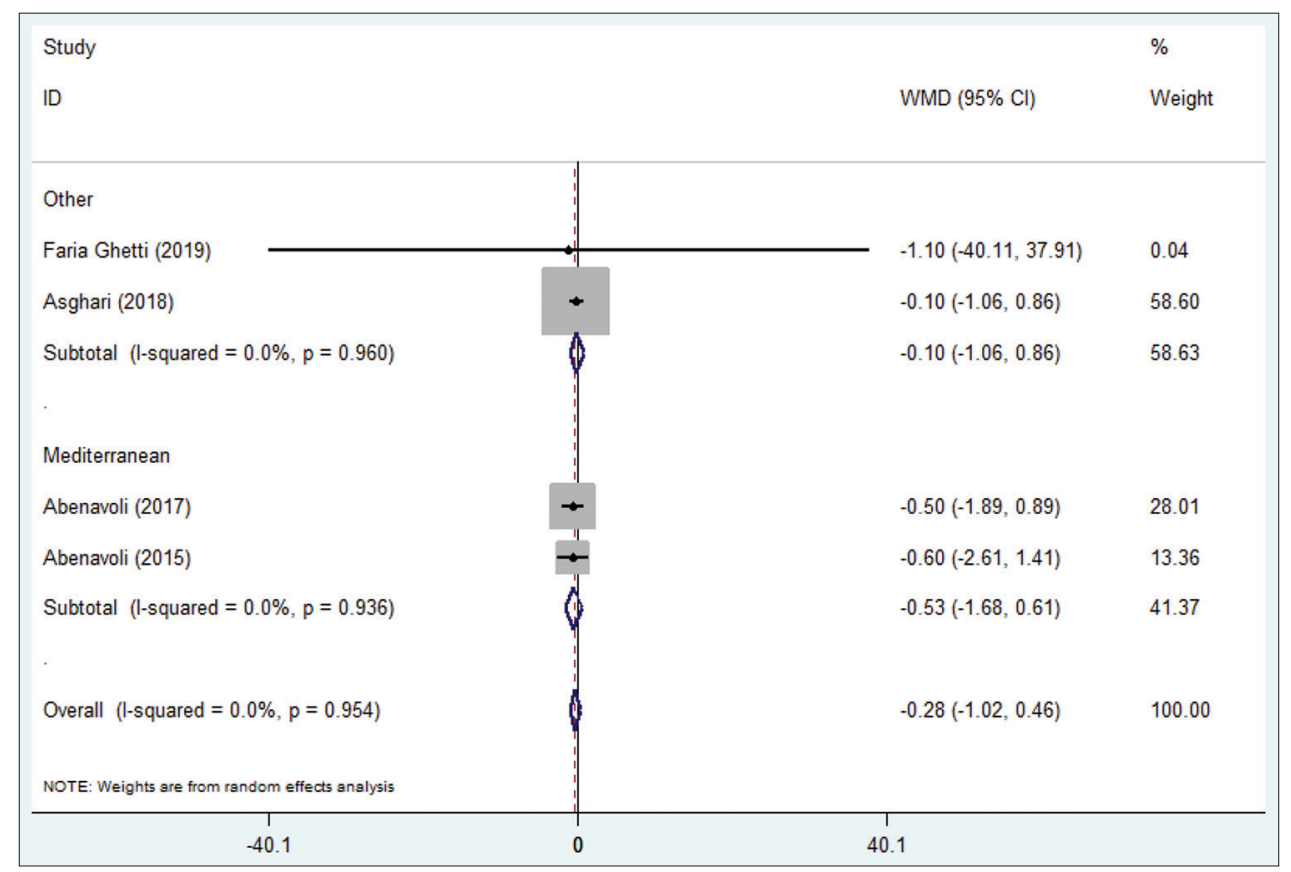

Supplementary Figure 3 Forest plot for the pooled weighted mean differences of diet interventions on homeostatic model assessment for insulin resistance based on random-effect model

$W M D$, weighted mean difference; $C I$, confidence interval

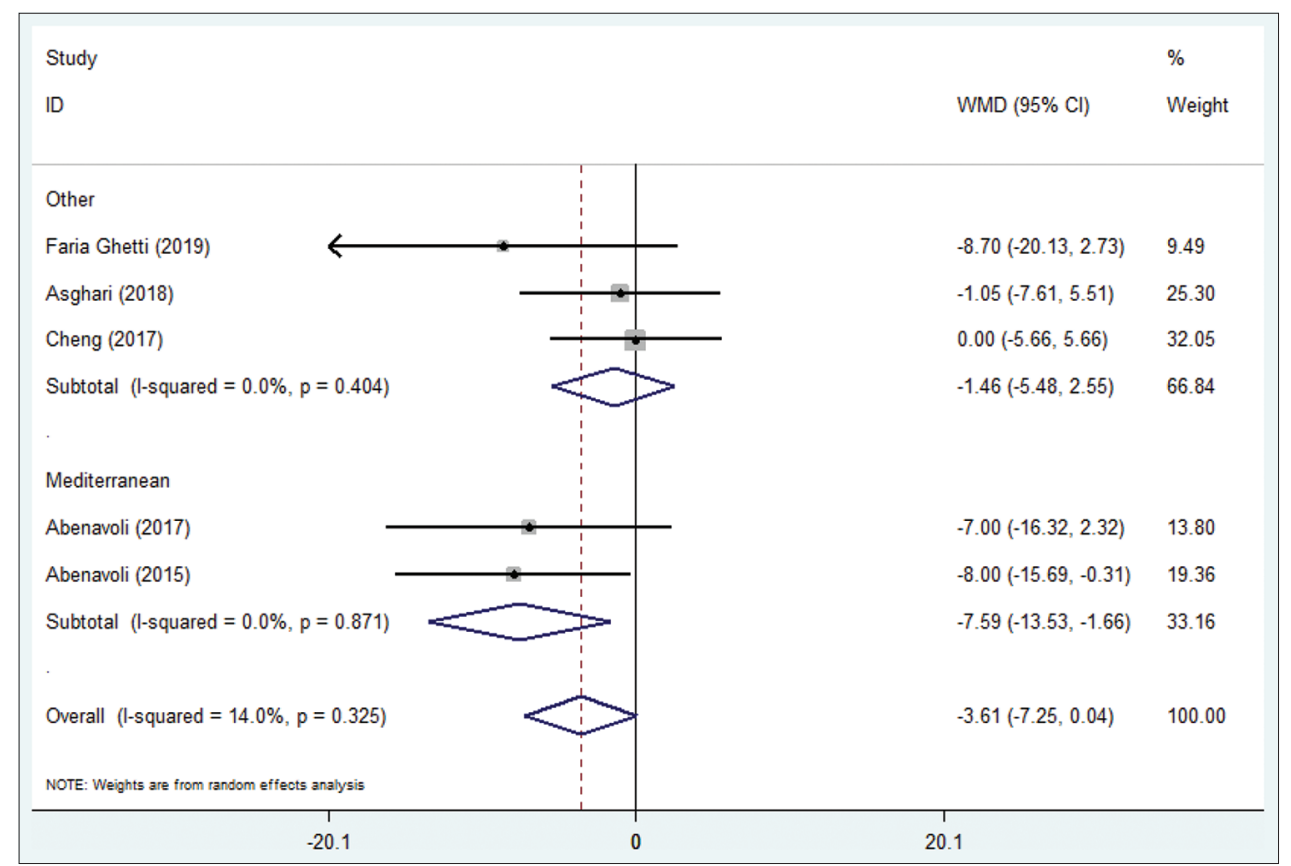

Supplementary Figure 4 Forest plot for the pooled weighted mean differences of diet interventions on weight based on random-effect model $W M D$, weighted mean difference; CI, confidence interval 